\title{
Allergic Reactions to Local Anesthetics in Dental Patients: Analysis of Intracutaneous and Challenge Tests
}

\author{
Yumiko Tomoyasu ${ }^{1}$, Kazuo Mukae ${ }^{2}$, Michiyo Suda $^{2}$, Tomoko Hayashi ${ }^{2}$, Minako Ishii ${ }^{2}$, \\ Mai Sakaguchi ${ }^{2}$, Yoshihisa Watanabe ${ }^{2}$, Ayako Jinzenji ${ }^{2}$, Yukiko Arai ${ }^{2}$, Hitoshi Higuchi ${ }^{3}$, \\ Shigeru Maeda ${ }^{1}$ and Takuya Miyawaki ${ }^{2}{ }_{*}$ \\ ${ }^{I}$ Department of Dental Anesthesiology, Okayama University Hospital, Okayama, Japan \\ ${ }^{2}$ Department of Dental Anesthesiology and Special Care Dentistry, Okayama University Graduate School of Medicine, \\ Dentistry and Pharmaceutical Sciences, Okayama, Japan \\ ${ }^{3}$ Department of Medical Genetics, University of Wisconsin-Madison, Madison, USA
}

\begin{abstract}
Some dental patients have histories of adverse reactions to local anesthesia. The aim of the present study was to investigate the frequency of allergy to local anesthetics of dental patients who had histories of adverse reactions to local anesthesia based on the results of allergy tests in our institute over a period of 5 years. We investigated the past medical records of dental patients retrospectively, and twenty patients were studied. Three of the 20 showed a positive or false-positive reaction in the intracutaneous test, and one patient showed a false-positive reaction in the challenge test. Our results suggest that the frequency of allergy to local anesthetics is low even if patients have histories of adverse reactions to local anesthesia. However, allergy tests of local anesthetics should be performed in patients in whom it is uncertain whether they are allergic.
\end{abstract}

Keywords: Local anesthetics, Adverse reaction, Allergic reaction, Intracutaneous test, Challenge test.

\section{INTRODUCTION}

Some dental patients have histories of adverse reactions to local anesthesia. Such adverse reactions are caused by intoxication (overdose), which results from intravascular injection or the rapid absorption of high doses of drugs, side effects associated with vasoconstrictors, the vasovagal reflex, anxiety, and a psychosomatic reaction [1-4]. In reality, true allergic reactions to local anesthetics are rare $[5,6]$. It has been estimated that only about $1 \%$ of all reactions occurring during local anesthesia are allergic in origin [7]. Allergic reactions have been shown to be caused by co-incidental exposure to other antigens such as preservatives (e.g., methyl-p-hydroxybenzoate), antioxidants (e.g., bisulphate), antiseptics (e.g., chlorhexidine), and other antigens such as latex, as well as local anesthetic drugs [8-10]. Many patients with histories of adverse reactions to local anesthesia have the impression that they are allergic to local anesthetics. In our institute, we have performed allergy tests in patients with histories of adverse reactions to local anesthesia. The test is mainly for detecting immediate allergy (anaphylaxis), because it rapidly occurs and is the most severe of all allergic reactions, resulting in potentially fatal consequences.

The aim of the present study was to investigate the frequency of allergy to local anesthetics in dental patients with

*Address correspondence to this author at Department of Dental Anesthesiology and Special Care Dentistry, Okayama University Graduate School of Medicine, Dentistry and Pharmaceutical Sciences; 2-5-1 Shikata-cho, Kitaku, Okayama 700-8525, Japan; Tel/Fax: +81-86-235-6721;

E-mail:miyawaki@md.okayama-u.ac.jp histories of adverse reactions to local anesthesia based on the results of allergy tests in our institute over a period of 5 years.

\section{PATIENTS AND METHODS}

This study was approved by the Ethics Committee of Okayama University Graduate School of Medicine, Dentistry and Pharmaceutical Sciences (No. 358). We investigated the past medical records of dental patients retrospectively. In the period from April 2004 to March 2009, twenty patients ( 3 males and 17 females) with histories of adverse reactions to local anesthesia were studied. The age was 45.2 \pm 16.8 years old, ranging from 17 to 77 . Ten patients had other allergens, including other drugs such as cephalosporium antibiotics, metals, alcohol, animals, house dust, pollen, and foods such as fish, eggs, milk, and soybean products. Four patients had a history of skin manifestations as the clinical symptoms of adverse reactions after the injection of local anesthetics, six had circulatory symptoms, three had respiratory symptoms, eight had central nervous symptoms, and three had other symptoms. According to the guidelines proposed by Barbaud, et al. [11], patients who have histories of erythema multiforme, Stevens-Johnson syndrome, toxic epidermal necrolysis, or leucocytoclastic vasculitis on histological examination caused by local anesthetics should be excluded from allergy tests. However, none of our patients showed such conditions.

We took precautions for emergency treatment, regularly monitoring the blood pressure, pulse, and electrocardiogram during the allergy test. Intracutaneous tests were performed in seventeen patients, challenge tests were conducted in thir- 
Table 1. Criteria for General Symptoms in the Challenge Test

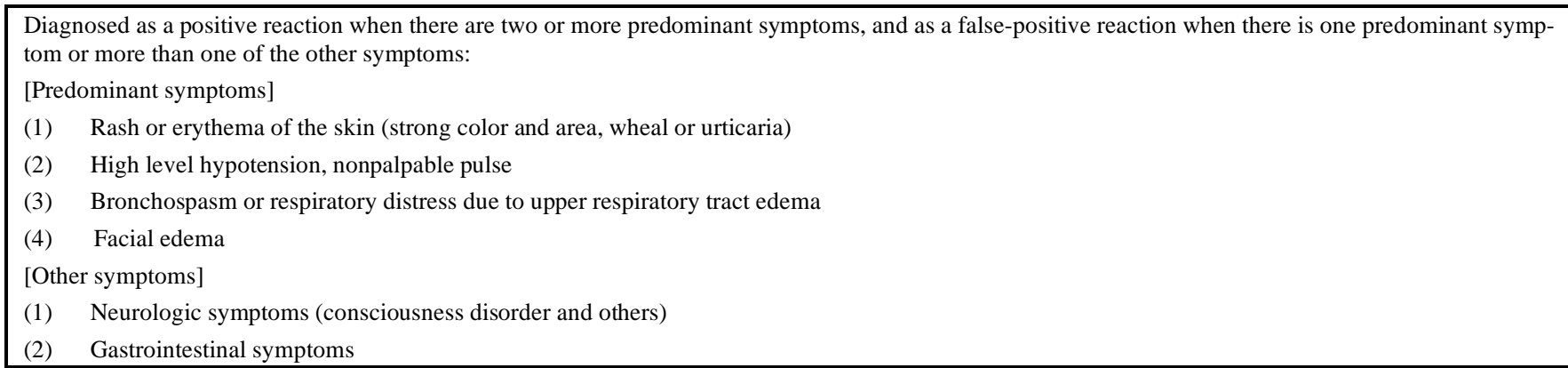

Table 2. Anesthetics and Adjuvants Contained in the Commercial Products Used for Allergy Tests

\begin{tabular}{|c|c|c|c|c|}
\hline \multirow{2}{*}{ Trade Name } & \multirow{2}{*}{ Anesthetic (Per/ml) } & \multicolumn{3}{|c|}{ Adjuvant (Per/ml) } \\
\hline & & Adrenaline & Sodium Pyrosulfite & Methyl-Paraben \\
\hline Xylocaine ${ }^{\circledR}$ Injection Polyamp $2 \%$ & Lidocaine hydrochloride $(20 \mathrm{mg}$ ) & $(-)$ & $(-)$ & $(-)$ \\
\hline Xylocaine ${ }^{\circledR}$ Injection $2 \%$ & Lidocaine hydrochloride $(20 \mathrm{mg}$ ) & $(-)$ & $(-)$ & $1 \mathrm{mg}$ \\
\hline $\begin{array}{l}\text { Xylocaine }{ }^{\circledR} \text { Cartridge } \\
\text { for Dental Use }\end{array}$ & Lidocaine hydrochloride $(20 \mathrm{mg}$ ) & $0.0125 \mathrm{mg}$ & $0.6 \mathrm{mg}$ & $1 \mathrm{mg} *$ \\
\hline Scandonest ${ }^{\circledR}$ cartridge 3\% & $\begin{array}{l}\text { Mepivacaine hydrochloride } \\
\qquad(30 \mathrm{mg})\end{array}$ & $(-)$ & $(-)$ & $(-)$ \\
\hline
\end{tabular}

*Methylparaben has not used since 2007

teen, and both were carried out in ten patients. The commercial products of local anesthetics injected for intracutaneous tests were as follows: Xylocaine ${ }^{\circledR}$ Injection Polyamp 2\% for eight patients, Xylocaine ${ }^{\circledR}$ Injection $2 \%$ for two patients, Scandonest ${ }^{\circledR}$ cartridge $3 \%$ for one patient, Xylocaine ${ }^{\circledR}$ Injection Polyamp 2\% and Scandonest $\AA$ cartridge $3 \%$ for three patients, and Xylocaine ${ }^{\circledR}$ Injection Polyamp 2\% plus Xylocaine ${ }^{\circledR}$ Injection $2 \%$ for two patients. On the other hand, the commercial products of local anesthetics injected for challenge tests were as follows: Xylocaine ${ }^{\circledR}$ Cartridge for Dental Use in eight patients, Xylocaine ${ }^{\circledR}$ Injection Polyamp $2 \%$ in three patients, Scandonest $\AA$ cartridge $3 \%$ in one patient, $\mathrm{Xy}$ locaine ${ }^{\circledR}$ Cartridge for Dental Use plus Xylocaine ${ }^{\circledR}$ Injection Polyamp $2 \%$ in one patient, and Xylocaine ${ }^{\circledR}$ Cartridge for Dental Use plus Xylocaine ${ }^{\circledR}$ Injection $2 \%$ in one patient.

Our methods for detecting immediate allergy to local anesthetics were as follows:

\section{1) Intracutaneous Test:}

An intracutaneous test was performed using local anesthetics, including lidocaine hydrochloride (Xylocaine ${ }^{\circledR}$ Injection Polyamp 2\%, AstraZeneca K.K. Osaka, Japan or Xylocaine ${ }^{\circledR}$ Injection 2\%, AstraZeneca K.K. Osaka, Japan) and mepivacaine hydrochloride (Scandonest ${ }^{\circledR}$ cartridge 3\%, Nippon Shika Yakuhin Co., Ltd., Yamaguchi, Japan). Some agents were diluted sequentially (1/100 or $1 / 10)$ with $0.9 \%$ saline, if needed. Local anesthetics were injected on the extensor surface of the arm in a small volume $(0.02 \mathrm{ml})$ that produces a wheal of a few $\mathrm{mm}$ in diameter. As a negative control, saline was injected. Redness or swelling in the area around the injection site was measured every 5 minutes until 20 minutes, and the judgments were as follows: a positive response, redness of more than $20 \mathrm{~mm}$; a false-positive response, redness of 10-19 $\mathrm{mm}$; or a negative response, redness of less than $10 \mathrm{~mm}$ in diameter. When general symptoms, which were applicable to the criteria, occurred at the time of the test, we judged it to be a false-positive or positive response.

\section{2) Challenge Test:}

Following the intracutaneous test, a challenge test was performed using the local anesthetics, including lidocaine hydrochloride (Xylocaine ${ }^{\circledR}$ Injection Polyamp 2\%, AstraZeneca K.K. Osaka, Japan or Xylocaine® Injection $2 \%$, AstraZeneca K.K. Osaka, Japan), lidocaine hydrochloride with $0.0125 \mathrm{mg}$ adrenaline per $1 \mathrm{ml}$ of lidocaine (Xylocaine ${ }^{\circledR}$ Cartridge for Dental Use, Dentsply-Sankin, Tokyo, Japan), and mepivacaine hydrochloride (Scandonest ${ }^{\circledR}$ cartridge $3 \%$, Nippon Shika Yakuhin Co., Ltd., Yamaguchi, Japan). One or two kinds of anesthetic were injected into the oral mucosa in a dose range from 0.1 to $1.0 \mathrm{ml}$ incrementally, and local findings around the injection site, general symptoms, and vital signs were observed until 30 minutes. The criteria for general symptoms in the challenge test are shown in Table $\mathbf{1 .}$

Table 2 shows the anesthetics and adjuvants contained in commercial products used for the allergy tests.

\section{RESULTS}

The results of intracutaneous tests showed a positive reaction to Scandonest ${ }^{\circledR}$ cartridge $3 \%$ in one patient, false- 


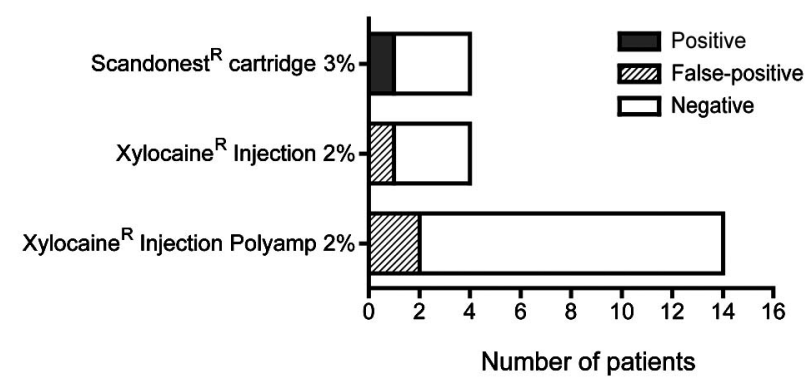

Fig. (1). The rates of patients showing a positive, false-positive, or negative reaction to local anesthetics in intracutaneous tests.

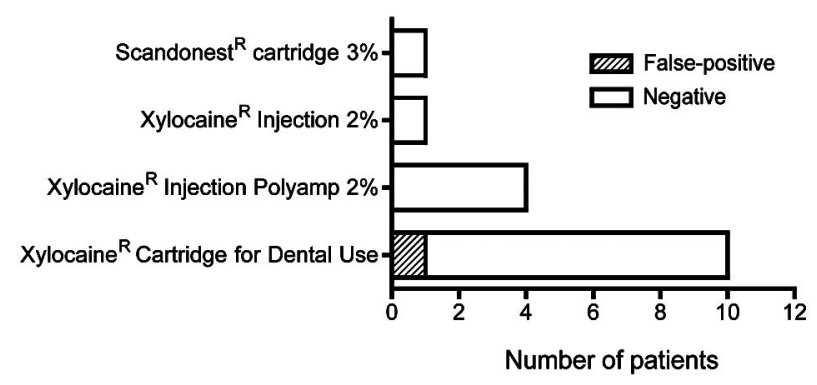

Fig. (2). The rates of patients showing a false-positive or negative reaction to local anesthetics in challenge tests. There were no patients with a positive reaction.

positive reactions to Xylocaine ${ }^{\circledR}$ Injection Polyamp 2\% and Xylocaine ${ }^{\circledR}$ Injection $2 \%$ in one patient, and a false-positive reaction to Xylocaine ${ }^{\circledR}$ Injection $2 \%$ in one patient (Fig. 1). A challenge test for the patient who showed a positive reaction on the intracutaneous injection of Scandonest ${ }^{\circledR}$ was avoided. The results of the challenge test showed a falsepositive reaction to Xylocaine ${ }^{\circledR}$ Cartridge in one patient (Fig. 2).

For the overall results of all tests, three patients showed a positive or false-positive reaction to local anesthetics. Detailed results for each case are as follows:

\section{Case 1:}

This patient was a 54-year-old woman. She had been di-

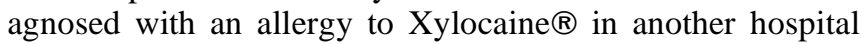
through a previous allergy test, so an allergy test for another local anesthetic for dental treatment was needed. This resulted in a positive reaction to Scandonest ${ }^{\circledR}$ in the intracutaneous test, suspected to be a true allergy.

\section{Case 2:}

This patient was a 57-year-old man. She had a history of losing consciousness when receiving local anesthesia for dental treatment. The patient showed false-positive reactions to Xylocaine ${ }^{\circledR}$ Injection Polyamp $2 \%$ and Xylocaine ${ }^{\circledR}$ Injection $2 \%$ in intracutaneous tests, and so underwent tooth extraction under general anesthesia a few days later. There was no problem on tooth extraction.

\section{Case 3:}

This patient was a 68-year-old woman. She had a history of dyspnea when receiving local anesthesia for dental treatment. The patient showed a false-positive reaction to Xylo- caine ${ }^{\circledR}$ Injection Polyamp $2 \%$ in the intracutaneous test and a false-positive reaction to Xylocaine ${ }^{\circledR}$ Cartridge for Dental Use in the challenge test, suspected to be immediate allergy (anaphylaxis). She underwent dental treatment using diphenhydramine hydrochloride as an alternative to local anesthetic a few days later $\left(\right.$ Venasmin ${ }^{\circledR}$ Injection $3 \%$ ), which has been reported to be as effective as local anesthesia. There was no problem with the dental treatment.

\section{DISCUSSION}

The intracutaneous test is a simple and easy method and has often been used as a means of identifying safe local anesthetics for patients with histories of adverse reactions [12]. However, it has been reported to be of no value in the diagnosis of reactions to local anesthetics [13] because it is unclear whether an adverse reaction is due to a local anesthetics or other factors [4]. The molecular weight of a local anesthetic is too low to elicit a positive reaction in a skin test even if the patient has an allergy to a local anesthetic [14]. On the other hand, provocative challenge has been thought to be the gold standard for the diagnosis of drug allergy [2]. Since there is no reliable in vitro test for allergy, the challenge test, which confirms the reproduction of symptoms by administering drugs, is thought to be the most reliable. However, because there is a possibility of causing an immediate allergy (anaphylaxis) at the time of the test, it is essential to obtain all relevant medical information from patients and perform the challenge test in an environment with an appropriate emergency system.

It is possible that every drug may cause an allergic reaction to some people, but it is difficult to predict this before administration. Local anesthetics are some of the rarest drug allergens. Our results suggest that the frequency of allergy to local anesthetics is low even if patients have histories of adverse reactions to local anesthesia. However, there are some patients with possible allergy to local anesthetics. In such cases, we have to prepare alternative agents. A candidate offering an alternative to local anesthetics is diphenhydramine hydrochloride, with an effect reportedly equal to $1 \%$ lidocaine and no crossreactivity to local anesthetics [15]. It was used in case 3 in our institute, resulting in no problem on tooth extraction. In other cases, some of these patients will have to receive general anesthesia for dental treatment without local anesthesia. We have to explain the alternatives to local anesthesia if a patient has a possible allergy to local anesthetics.

An allergy to local anesthetics is thought to be a type IV reaction at rates of between 80 and $90 \%$. This means that the majority of allergic reactions occur as allergic contact dermatitis [16]. Because the frequency of adding local anesthetics to general commercial drugs is gradually increasing, resulting in an increase in the frequency of sensitization, rates of allergy to local anesthetics may increase in the future. Therefore, we will have more opportunities to investigate allergy to local anesthetics. Dentists, who often use local anesthetics, have to pay more attention to such allergy. Allergy tests of local anesthetics should be performed in patients in whom it is uncertain if they are allergic, and patients should undergo dental treatment only after it has been confirmed that a local anesthetic can be used safely. 


\section{REFERENCES}

[1] Giovannitti JA, Bennett CR. Assessment of allergy to local anesthetics. J Am Dent Assoc 1979; 98: 701-6.

[2] Berkun Y, Ben-Zvi A, Levy Y, Galili D, Shalit M. Evaluation of adverse reactions to local anesthetics: experience with 236 patients. Ann Allergy Asthma Immunol 2003; 91: 342-5.

[3] Malamed SF, Sykes P, Kubota Y, Matsuura H, Lipp M. Local anesthesia: a review. Anesth Pain Control Dent 1992; 1: 11-24.

[4] Adriani J, Zepernick R. Allergic reactions to local anesthetics. South Med J 1981;74: 694-9, 703.

[5] Adriani J. Etiology and management of adverse reactions to local anesthetics. Int Anesthesiol Clin 1972; 10: 127-51.

[6] Fisher MM, Bowey CJ. Alleged allergy to local anaesthetics. Anaesth Intensive Care 1997; 25: 611-4.

[7] Monheim LM. Monheim's local anesthesia and pain control in dental practice. St. Louis, Mosby Co 1978; 162-6.

[8] Wildsmith JA, Mason A, McKinnon RP, Rae SM. Alleged allergy to local anaesthetic drugs. Br Dent J 1998; 184: 507-10.

[9] Kelly KJ, Walsh-Kelly CM. Latex allergy: a patient and health care system emergency. J Emerg Nurs 1998; 24: 539-45.
[10] Schwartz HJ, Sher TH. Bisulfite sensitivity manifesting as allergy to local dental anesthesia. J Allergy Clin Immunol 1985; 75: 525-7.

[11] Barbaud A, Goncalo M, Bruynzeel D, Bircher A. Guidelines for performing skin tests with drugs in the investigation of cutaneous adverse drug reactions. Contact Dermatitis 2001; 45: 321-8.

[12] Schatz M. Skin testing and incremental challenge in the evaluation of adverse reactions to local anesthetics. J Allergy Clin Immunol 1984; 74: 606-16.

[13] Fisher MM. Intradermal testing in the diagnosis of acute anaphylaxis during anaesthesia--results of five years experience. Anaesth Intensive Care 1979; 7: 58-61.

[14] Aldrete JA, Johnson DA. Evaluation of intracutaneous testing for investigation of allergy to local anesthetic agents. Anesth Analg 1970; 49: 173-83.

[15] Green SM, Rothrock SG, Gorchynski J. Validation of diphenhydramine as a dermal local anesthetic. Ann Emerg Med 1994; 23: 1284-9.

[16] Thyssen JP, Menne T, Elberling J, Plaschke P, Johansen JD. Hypersensitivity to local anaesthetics--update and proposal of evaluation algorithm. Contact Dermatitis 2008; 59: 69-78.

(C) Tomoyasu et al.; Licensee Bentham Open.

This is an open access article licensed under the terms of the Creative Commons Attribution Non-Commercial License (http://creativecommons.org/licenses/by-nc/3.0/) which permits unrestricted, non-commercial use, distribution and reproduction in any medium, provided the work is properly cited. 